\title{
Gender differences in COVID-19 patients: a regional survey among physicians of Internal Medicine Wards
}

\author{
Tiziana Ciarambino, ${ }^{1}$ Alfonso Ilardi, ${ }^{2}$ Orazio Valerio Giannico, ${ }^{3}$ Ada Maffettone, ${ }^{4}$ Filippina Ciaburri,${ }^{2}$ \\ Venere Delli Paoli, ${ }^{2}$ Andrea Fontanella, ${ }^{5}$ Paolo Tirelli, ${ }^{6}$ Carolina Bologna, ${ }^{6}$ Fernando Gallucci, ${ }^{2}$ Mario Visconti, \\ Domenico Caruso, ${ }^{2}$ Maria Amitrano, ${ }^{8}$ Mauro Giordano, ${ }^{9}$ Maria D’Avino, ${ }^{2}$ on behalf of FADOI Campania Board \\ ${ }^{1}$ Internal Medicine Department, Hospital of Marcianise, ASL Caserta; ${ }^{2}$ Internal Medicine Department, AORN Cardarelli \\ Napoli; ${ }^{3}$ Department of Prevention, ASL Taranto; ${ }^{4}$ Internal Medicine Department, Ospedale Monaldi Napoli; ${ }^{5}$ Internal Medi- \\ cine Department, Ospedale Fatebenefratelli, Napoli; ${ }^{\circ}$ Internal Medicine Department, Ospedale del Mare, Napoli; \\ ${ }^{7}$ Emeritus Chief of Internal Medicine, ASL Napoli 1, Napoli; ${ }^{8}$ Internal Medicine Department, AORN Moscati Avellino; \\ ${ }^{9}$ Internal Medicine Department, University of Campania, L. Vanvitelli, Napoli, Italy
}

\begin{abstract}
Severe acute respiratory syndrome-related coronavirus 2 (SARS-CoV-2) has infected millions of individuals around the World. Hypertension (HT), chronic heart disease (CHD), and diabetes mellitus (DM), particularly in the elderly, increase susceptibility to SARS-CoV-2 infection. However, conflicting results [such as coronavirus 2019 (COVID-19) disease vulnerability, case fatality, etc.] have been reported about the response to infection and COVID-19 outcomes in men and women. Therefore, understanding predictors of Intensive Care Unit (ICU) admission might help future planning and management of the disease. We conducted a multicenter survey about COVID-19 involving internists from Internal Medicine Wards. This survey indirectly allowed us to analyze the information of 2400 patients hospitalized in 35 wards of Internal Medicine of the Campania Region between July and October 2020. Our investigation has detected that the infection is more frequent in males, and the number of male patients hospitalized in ICU is also higher than females, with a large proportion of hypertensive patients. Extensive prospective studies are required to confirm this finding and explore the mechanisms for which hypertensive males are exposed to a higher proportion of admission to ICU and higher case fatality rates.
\end{abstract}

\section{Introduction}

Severe acute respiratory syndrome-related coronavirus 2 (SARS-CoV-2) has infected millions of indi-

Correspondence: Tiziana Ciarambino, Internal Medicine Department, Hospital of Marcianise, ASL Caserta, Italy.

E-mail: tiziana.ciarambino@gmail.com

Key words: Hypertensive; COVID-19; gender differences; arterial hypertension.

Acknowledgments: we thank the doctor Cecilia Politi, Responsabile AREA Medicina di Genere FADOI, Italy.

Contributions: all named authors take responsibility for the integrity of the work as a whole and have given final approval for the version to be published.

Conflict of interests: the authors declare no potential conflict of interests.

Received for publication: 8 December 2020.

Revision received: 18 March 2021.

Accepted for publication: 9 April 2021.

This work is licensed under a Creative Commons Attribution NonCommercial 4.0 License (CC BY-NC 4.0).

${ }^{\circ}$ Copyright: the Author(s), 2021

Licensee PAGEPress, Italy

Italian Journal of Medicine 2021; 15:160-163

doi:10.4081/itjm.2021.1443 viduals worldwide: up to $22^{\text {nd }}$ November about 58 million cases have been reported, with more than one million deaths. ${ }^{1}$ The elderly and people with chronic conditions, such as hypertension and diabetes mellitus, show increased morbidity and are more likely to be hospitalized and admitted to Intensive Care Units (ICUs). These considerations seem to be particularly true for hypertensive patients. ${ }^{2-4}$ The analysis by gender has reported a similar number of men and women affected by SARS-CoV-2 infection, although mortality seems higher in men. In this regard, it has been reported that the male gender is also more sensitive due to the higher number of smokers in men than in women. ${ }^{5}$ In addition to lifestyle habits, other genderrelated aspects - including metabolism, immunologic reactivity, and drug response- have been described as potential explanations for these observations. ${ }^{6}$ These preliminary findings highlight the need to identify the predictors of admission to ICU, which, appropriately diversified by gender, can be useful for managing SARS-CoV-2 infection.

\section{Materials and Methods}

We conducted a multicenter survey involving physicians who attended to patients affected by coronavirus disease 2019 (COVID-19) and hospitalized in 
Campania in July-October 2020. The physicians are not included in the study population for evaluating the outcome, case fatality etc. Only the respondents who answered all the questions were included in the final sample, pre-specifying that the average time to complete the survey was ten minutes and that the participants would receive no incentive for its completion. Among the 85 wards of Internal Medicine in the region, 35 of them (41\%) have agreed to join the study. The database was too big to be included in the article. Moreover, to better explain the kind of data, we specify that the data set consists of 2400 records, i.e., every hospital that had answered the survey. For each hospital, the returned data (the answers) were continuous data (e.g., the number of male nurses, the number of female patients, etc.) It is performed under article 89 of the General Data Protection and Regulation, which allows the processing of personal data for archiving purposes in the public interest, scientific or historical research purposes, or statistical purposes, provided that technical and organizational measures are in place to ensure the principle of data minimization. ${ }^{7,8} \mathrm{An}$ online questionnaire was distributed among the Internal Medicine wards to collect epidemiological, clinical, and outcomes data about COVID-19 patients, followed throughout their hospital stay, starting from the Emergency Room. Patients have been pseudonymized by assigning each one an identification code. Every Internal Medicine Ward specified at least one physician, trained in processing the information, collected and developed on 26 items. Twenty-four of these items describe a gender perspective (12 items for men and 12 for women) (Table 1). For example, it was surveyed, in relation to gender, how many health workers were currently on the ward; how many patients hospitalized from February 1 to date have been tested pos-

Table 1. Items included for the study.

\begin{tabular}{|c|c|c|}
\hline Item & Questions & Mean (standard deviation) \\
\hline A & Male physicians & $5.8(3.9)$ \\
\hline B & Female physicians & $4.6(5.6)$ \\
\hline $\mathrm{C}$ & Physicians and nurses & $12.3(9.2)$ \\
\hline $\mathrm{D}$ & Female nurses & $13.2(8.2)$ \\
\hline $\mathrm{E}$ & Male patients admitted to Internal Medicine Ward & $9.5(7.7)$ \\
\hline $\mathrm{F}$ & Female patients admitted to Internal Medicine Ward & $8.8(8.4)$ \\
\hline G & Male physicians positive for SARS-CoV-2 & $0.8(1.3)$ \\
\hline $\mathrm{H}$ & Female physicians positive for SARS-CoV-2 & $0.5(0.9)$ \\
\hline I & Male patients positive for SARS-CoV-2 & $8.1(14.3)$ \\
\hline $\mathrm{J}$ & Female patients positive for SARS-CoV-2 & $7.3(13.6)$ \\
\hline $\mathrm{K}$ & Male patients positive for SARS-CoV-2 have died & $1.6(2.5)$ \\
\hline $\mathrm{L}$ & Female patients positive for SARS-CoV-2 have died & $1.0(1.7)$ \\
\hline M & ADE COVID-19 related treatments have been recorded in male patients & $0.4(0.9)$ \\
\hline $\mathrm{N}$ & ADE COVID-19 related treatments have been recorded in female patients & $0.2(0.4)$ \\
\hline $\mathrm{O}$ & COVID positive male patients have required resuscitation therapy & $1.7(2.8)$ \\
\hline $\mathrm{P}$ & COVID positive female patients have required resuscitation therapy & $1.0(2.0)$ \\
\hline Q & COVID positive male patients had $\mathrm{P} / \mathrm{F}$ values $<300$ & $6.3(10.7)$ \\
\hline $\mathrm{R}$ & COVID positive female patients had $\mathrm{P} / \mathrm{F}$ values $<300$ & $3.2(6.4)$ \\
\hline $\mathrm{S}$ & COVID positive male patients had $\mathrm{P} / \mathrm{F}$ values $>300$ & $4.1(7.0)$ \\
\hline $\mathrm{T}$ & COVID positive female patients had $\mathrm{P} / \mathrm{F}$ values $>300$ & $3.9(7.3)$ \\
\hline $\mathrm{U}$ & COVID positive male patients had CRP values between $0.5-10 \mathrm{mg} / \mathrm{mL}$ & $3.5(7.5)$ \\
\hline $\mathrm{V}$ & COVID positive male patients had CRP values between $0.5-10 \mathrm{mg} / \mathrm{mL}$ & $3.7(7.8)$ \\
\hline W & COVID positive male patients had CRP values $>10 \mathrm{mg} / \mathrm{mL}$ & $6.4(9.8)$ \\
\hline $\mathrm{X}$ & COVID positive female patients had CRP values $>10 \mathrm{mg} / \mathrm{mL}$ & $3.8(6.3)$ \\
\hline Y & COVID positive male patients presented some comorbidities >3 & $7.2(12.3)$ \\
\hline $\mathrm{Z}$ & COVID positive female patients presented some comorbidities $>3$ & $5.4(9.9)$ \\
\hline
\end{tabular}

$\mathrm{ADE}$, adverse drug events; CRP, C-reactive protein. 
itive for COVID-19 (diagnosis confirmed by RT-PCR performed on nasopharyngeal or throat swab samples); among them, how many have died and how many COVID-positive patients had $\mathrm{P} / \mathrm{F}$ values $<300$ or $>300$; as well as how many patients showed C-Reactive Protein values between $0.5-10 \mathrm{mg} / \mathrm{mL}$ and how many above 10 . The number of comorbidities per patient was also assessed, including hematological or oncological morbidities. Ultimately, we collected outcomes, such as hospital discharge, admission to ICU, or death. The electronic data were transmitted with the modern cryptography systems over the web and stored in a locked, password-protected computer. All collected records were then quality checked by two authors (T.C. and V.D.P.). Statistical analysis was performed using R version 4.0.0 (released on 202004-24). Statistical significance $\alpha$ was fixed to 0.05 . Numerical variables were reported as mean (SD) and compared through paired t-test.

\section{Results}

On 35 hospital wards, the data of 2400 records (Table 1). While the difference between the two sexes regarding the positivity of the swab is not statistically significant, the difference in mortality is at the border of significance. Similarly, at the threshold of significance, the difference between COVID-positive males and females in need of admission to ICU. However, among patients admitted to ICU, the number of comorbidities was higher; overall, the number of morbidities was higher in COVID-positive males than in females (7.2 compare 5.4, $\mathrm{P}<0.05$ ). Also, in the context of comorbidities, the number of COVID-positive males with more than 3 morbidities was higher than the number of COVID-positive females. Furthermore, the gender difference in the exchange parameters was very significant since positive males with a $\mathrm{P} / \mathrm{F}<300$ were almost twofold compared to females (6.3 in males compared to 3.2 in females; $\mathrm{P}<0.05$ ). A similar gap was recorded for the two sexes concerning $\mathrm{C}$-reactive protein, for values $>10 \mathrm{mg} / \mathrm{mL}$ (6.4 in males compared to 3.8 in females; $\mathrm{P}<0.05$ ) (Table 2).

\section{Discussion}

We observed that males had a significantly higher proportion in COVID-19 infection than females with a higher fatality rate. Therefore, in our cohort and in agreement with those from other groups, the male gender is a risk factor for a poor clinical outcome. ${ }^{11}$ In particular, in males, a $\mathrm{P} / \mathrm{F}$ ratio $<300$ and higher C-reactive protein levels were more frequent. In addition, it has been widely reported that male patients were more frequently admitted to ICU, ${ }^{12}$ although this feature, in our survey, is at the border of significance. The explanation for the greater vulnerability of males to SARS-CoV-2 infection with a worse outcome remains largely unknown. ${ }^{12-14}$ In this regard, some hypotheses can be advanced both in an immuno-biological key. With aging, the functional competence of immune responses decreases, and this reduction is more remarkable in males. ${ }^{6}$ These functional changes, involving innate immunity and acquired specific immunity cells, are likely to increase the risk of autoimmune diseases and cancer. ${ }^{15-17}$

With regard to gender, significant differences between the two sexes have been reported. For example, it has been observed that the activity of pattern-recognition receptors, production of acute phase proteins (e.g., TNF- $\alpha$ ), and phagocytosis are higher in females than males. ${ }^{18-19}$ These features could explain a more vigorous response to microbial invasions and a more efficient elimination of microorganisms. In particular, the high production of IL- 6 in adipose tissue can act as a stimulus for hepatocytes to produce acute phase reactants such as C-reactive protein. ${ }^{20}$ The increased expression of adipose tissue, which is observed in the male with senescence, could be an additional factor in promoting the increase of C-reactive protein levels in baseline and even more so following an inflammatory trigger. ${ }^{21}$ According to literature search, our data involved high levels of IL- 6 and P/F ratio $<300$ in the male gender, as a crucial factor of the negative outcome. However, our data are in accordance with other studies about ICU admission in male patients. ${ }^{12} \mathrm{Be}-$ sides a wide range of factors, sex should be one of the criteria to consider to select the appropriate therapies for the right patient. That is why there is a need for extensive, unbiased studies that also account for gen-

Table 2. Paired t-test.

\begin{tabular}{lcc}
\hline Items comparison by Table 1 & Mean of differences & $\mathbf{P}$ \\
\hline A-B & 1.1 & 0.151 \\
\hline C-D & -0.9 & 0.591 \\
\hline E-F & 0.6 & 0.552 \\
\hline G-H & 0.2 & 0.056 \\
\hline I-J & 0.8 & 0.576 \\
\hline K-L & 0.6 & 0.055 \\
\hline M-N & 0.2 & 0.163 \\
\hline O-P & 0.8 & 0.055 \\
\hline Q-R & 2.9 & 0.034 \\
\hline S-T & -0.1 & 0.835 \\
\hline U-V & -0.2 & 0.617 \\
\hline W-X & 3.0 & 0.007 \\
\hline Y-Z & 1.8 & 0.037 \\
\hline
\end{tabular}


der differences, to find patient-tailored therapies. Our study has several limitations. First, the use of questionnaires may allow a certain level of uncertainty, especially for the risk of incomplete responses. The online survey is designed with closed-ended questions, all of which are required for final validation, thus reducing this hazard. Second, the survey includes hospitalized patients and assesses clinical features and outcomes only of patients with the confirmed disease by nasal or pharyngeal swabs. Therefore, we might have missed those patients with early infection and negative tests. Third, this study was conducted in few hospitals; the sample size and selection bias might limit therefore interpretation of our findings.

\section{Conclusions}

SARS-CoV-2 is a novel coronavirus that emerged in Wuhan (China) markets in late December 2019. It induces predominantly respiratory symptoms, but also other manifestations are possible, for example, cardiological or neurological. The prognosis is worse in the elderly and in multimorbid subjects, but there is also an important prognostic difference according to sex. In this matter, since the beginning of the outbreak, there has been increased morbidity and mortality among males. Concurrently, the number of males admitted to the ICU for COVID-19 is also higher. Our survey has confirmed this gender difference in the distribution of the disease, extending it to health care workers of the internal medicine ward, which are mainly represented by males among the medical staff.

\section{References}

1. European Centre for Disease Prevention and Control. COVID-19 situation update worldwide, as of 22 November 2020. Available from: https://www.ecdc.europa.eu/en/geographical-distribution-2019-ncov-cases

2. Fang L, Karakiulakis G, Roth M. Are patients with hypertension and diabetes mellitus at increased risk for COVID-19 infection? Lancet Respir Med 2020.

3. Zhang JJ, Dong X, Cao YY, et al. Clinical characteristics of 140 patients infected with SARS-CoV-2 in Wuhan, China. Allergy 2020;00:1-12.

4. Guan WJ, Ni ZY, Hu Y, et al. Clinical characteristics of coronavirus disease 2019 in China. N Engl J Med. 2020;382:1708-20.

5. Cai H. Sex difference and smoking predisposition in patients with COVID-19. Lancet Respir Med 2020;8:e20.

6. Ilardi A, Politi C, Ciarambino T. COVID-19: could sex and age be a risk factor? Minerva Med 2020 [Epub ahead of print].

7. WHO. Clinical management of severe acute respiratory infection when novel coronavirus $(\mathrm{nCoV})$ infection is suspected: interim guidance.

8. Intersoft Consulting. General data protection regulation (GDPR). Available from: https://gdpr-info.eu

9. Centers for Disease Control and Prevention (CDC). Defining adult overweight \& obesity. Available from: https://www.cdc.gov/obesity/adult/defining.html

10. Wu Z, McGoogan JM. Characteristics of and Important Lessons From the Coronavirus Disease 2019 (COVID19) Outbreak in China: Summary of a Report of 72314 Cases From the Chinese Center for Disease Control and Prevention. JAMA. 2020. [Epub ahead of print].

11. Ilardi A, Chieffi S, Iavarone A, Ilardi CR. SARS-CoV-2 in Italy: population density correlates with morbidity and mortality. Jpn J Infect Dis 2020 [Epub ahead of print].

12. Chen N, Zhou M, Dong X, et al. Epidemiological and clinical characteristics of 99 cases of 2019 novel coronavirus pneumonia in Wuhan, China: a descriptive study. Lancet 2020;395:507-13.

13. Iaccarino G, Grassi G, Borghi C, et al.; SARS-RAS Investigators. Gender differences in predictors of intensive care units admission among COVID-19 patients: the results of the SARS-RAS study of the Italian Society of Hypertension. PLoS One 2020;15:e0237297.

14. Zhang J, Wang X, Jia X, et al. Risk factors for disease severity, unimprovement, and mortality in COVID-19 patients in Wuhan, China. Clin Microbiol Infect 2020. [Epub ahead of print].

15. Gubbels Bupp MR, Potluri T, Fink AL, Klein SL. The confluence of sex hormones and aging on immunity. Front Immunol 2018;9:1269.

16. Giefing-Kröll C, Berger P, Lepperdinger G, GrubeckLoebenstein B. How sex and age affect immune responses, susceptibility to infections, and response to vaccination. Aging Cell 2015;14:309-21.

17. Gaya da Costa M, Poppelaars F, van Kooten C, et al. Age and sex-associated changes of complement activity and complement levels in a healthy Caucasian Population. Front Immunol 2018;9:2664.

18. Al-Attar A, Presnell SR, Peterson CA, et al. Data correlations between gender, cytomegalovirus infection and T cells, NK cells, and soluble immune mediators in elderly humans. Data Brief 2016;8:536-44.

19. Marttila S, Jylhävä J, Nevalainen T, et al. Transcriptional analysis reveals gender-specific changes in the aging of the human immune system. PLoS One 2013;8:e66229.

20. Khera A, McGuire DK, Murphy SA, et al. Race and gender differences in C-reactive protein levels. J Am Coll Cardiol 2005;46:464-9.

21. Lambert DW, Yarski M, Warner FJ, et al. Tumor necrosis factor-alpha convertase (ADAM17) mediates regulated ectodomain shedding of the severe-acute respiratory syndrome-coronavirus (SARS-CoV) receptor, angiotensin-converting enzyme-2 (ACE2). J Biol Chem 2005;280:30113-9. 